\title{
Analisis Kapasitas Seismik Struktur Gedung Kantor Dinas Ketahanan Pangan Provinsi Sumatra Barat
}

\author{
Thasbih Al Fajri ${ }^{1}$, Rafki Imani ${ }^{2}$, Zakpar Siregar ${ }^{3}$ \\ ${ }^{1}$ Universitas Putra Indonesia YPTK Padang, Indonesia \\ ${ }^{2}$ Universitas Putra Indonesia YPTK Padang, Indonesia \\ ${ }^{3}$ Universitas Putra Indonesia YPTK Padang, Indonesia
}

Email: Thasbihalfajri@gmail.com,rafki.iman@gmail.com, zakparsir@yahoo.com

\begin{abstract}
The office building of the food security office of West Sumatra Province is a multi-storey building with reinforced concrete structures built in earthquake-prone areas that have the potential for large-scale earthquakes such as the one that occurred in 2009. Based on USGS data, from December 2004 to October 2009 There have been 10 earthquakes measuring more than 5 on the Richter scale that rocked Indonesia and resulted in damage to buildings, both minor damage to heavy damage and even collapsing. The big earthquake that occurred on September 30, 2009 in Padang City, West Sumatra, was measuring 7.6 on the Richter scale. In this study, evaluated the seismic capacity of a reinforced concrete building 4 (four) floors built in earthquake-prone areas in the city of Padang. The seismic capacity of the building is evaluated based on the standard published by Japan, namely The Standard for Seismic Evaluation of Existin Reinforced Concrete Building, 2001. In this evaluation, it only looks at the structural elements of the column on the first floor. Seismic capacity is expressed in terms of the lateral strength index and the ductility index of the building. The results of the evaluation of seismic capacity obtained the total strength index value of the building is 0.707 . The seismic capacity of this building can be shown to be adequate or strong in earthquake-prone areas compared to the seismic capacity of reinforced concrete buildings that survived the massive earthquake of 7.6 on the Richter Scale in West Sumatra in September 2009. From the evaluation results on this building which is located in an area including the prone to strong earthquakes can be stated to be able to behave ductile and able to withstand an earthquake or not experience sudden collapse.
\end{abstract}

Keywords: Seismic capacity, reinforced concrete, large earthquake, ductile

\begin{abstract}
Abstrak
Gedung kantor dinas ketahanan pangan Provinsi Sumatra Barat merupakan bangunan gedung bertingkat dengan struktur beton bertulang yang dibangun di daerah rawan gempa yang berpotensi akan terjadinya gempa beskala besar seperti yang pernah terjadi pada tahun 2009. Berdasarkan data USGS, dari rentang waktu antara Desember 2004 sampai Oktober 2009 telah terjadi 10 gempa berkekuatan lebih dari 5 skala richter yang mengguncang indonesia dan mengakibatkan kerusakan pada bangunan baik kerusakan ringan hingga kerusakan berat bahkan roboh. Gempa besar yang terjadi pada 30 September 2009 di Kota Padang Sumatera Barat berkekuatan 7,6 Skala Richter. Dalam penelitian ini dievaluasi kapasitas seismik bangunan gedung beton bertulang 4 (empat) lantai yang dibangun pada daerah rawan gempa di Kota Padang. Kapasitas seismik bangunan dievaluasi berdasarkan standar yan dipublikasikan oleh Jepang, yaitu The Standard for Seismic Evaluation of Existin Reinforced Concrete Building, 2001. Dalam evaluasi ini hanya meninjau elemen struktu kolom pada lantai satu. Kapasitas seismik diyatakan dalam hubungan antara indeks kekuatan lateral dan indeks daktilitas bangunan. Hasil dari evaluasi kapasitas seismik didapatkan nilai indeks kekuatan total bangunan gedung adalah 0,707. Kapasitas seismik gedung ini bisa dinyatkan memadai atau kuat pada daerah rawan gempa dibandingkan dengan kapasitas seismik gedung beton bertulang yang bertahan akibat gempa besar 7,6 Skala Richter di Sumatra Barat pada September 2009. Dari hasil evaluasi pada bangunan ini yang berlokasi di daerah yang termasuk daerah rawan gempa kuat dapat dinyatakan mampu berperilaku daktail dan mampu bertahan sewaktu gempa atau tidak mengalami keruntuhan secara tiba-tiba.
\end{abstract}

Kata kunci: kapasitas Seismik, beton bertulang, gempa besar, daktail.

\section{Pendahuluan}

Indonesia termasuk kategori daerah dengan resiko gempa yang tinggi khusus nya pada rentang waktu tahun 2004 sampai 2009 dimana berdasarkan data USGS telah terjadi 10 gempa besar berkekuatan lebih dari 5 skala richter yang mengguncang indonesia. Salah satu gempa. besar yang terjadi yaitu pada daerah rawan gempa di Provinsi Sumatra Barat Kota Padang pada 30 September 2009 dengan kekuatan 7,6 Skala richter yang menyebabkan banyak terjadi kerusakan bahkan keruntuhan pada bangunan gedung beton bertulang. Ketahanan bangunan terhadap gelombang getaran atau seismik dilihat dari pelaksanaan konstruksi dan perencanaan konstruksi.

Dalam merencanakan suatu bangunan, perencana harus meninjau daerah yang akan dibangun terlebih dahulu dan menerapkan standar-standar yang perlu diperhatikan agar bangunan dapat bertahan sewaktu gempa terjadi. Dalam hal ini untuk mengetahui hal tersebut, dilakukan analisis seismik pada bangunan Dinas Ketahanan Pangan

Diterima Redaksi : 16-10-2020 | Selesai Revisi : 27-10-2020 | Diterbitkan Online : 31-10-2020 
Provinsi Sumatra Barat Kota Padang. Salah satu metoda analisis seismik dengan mengacu pada Standar for seismic Evaluation of Existing Reinforced Concrete Building yang diterbitkan oleh The Japan Building Disaster Prevention Association. Analisis seismik pada bangunan struktur beton bertulang ini diharapkan dapat memberikan gambaran tentang kapasitas seismik pada bangunan gedung bertingkat dengan kapasitas seismik diberikan dalam bentuk hubunan antara indeks kekuatan lateral dan indeks daktilitas.

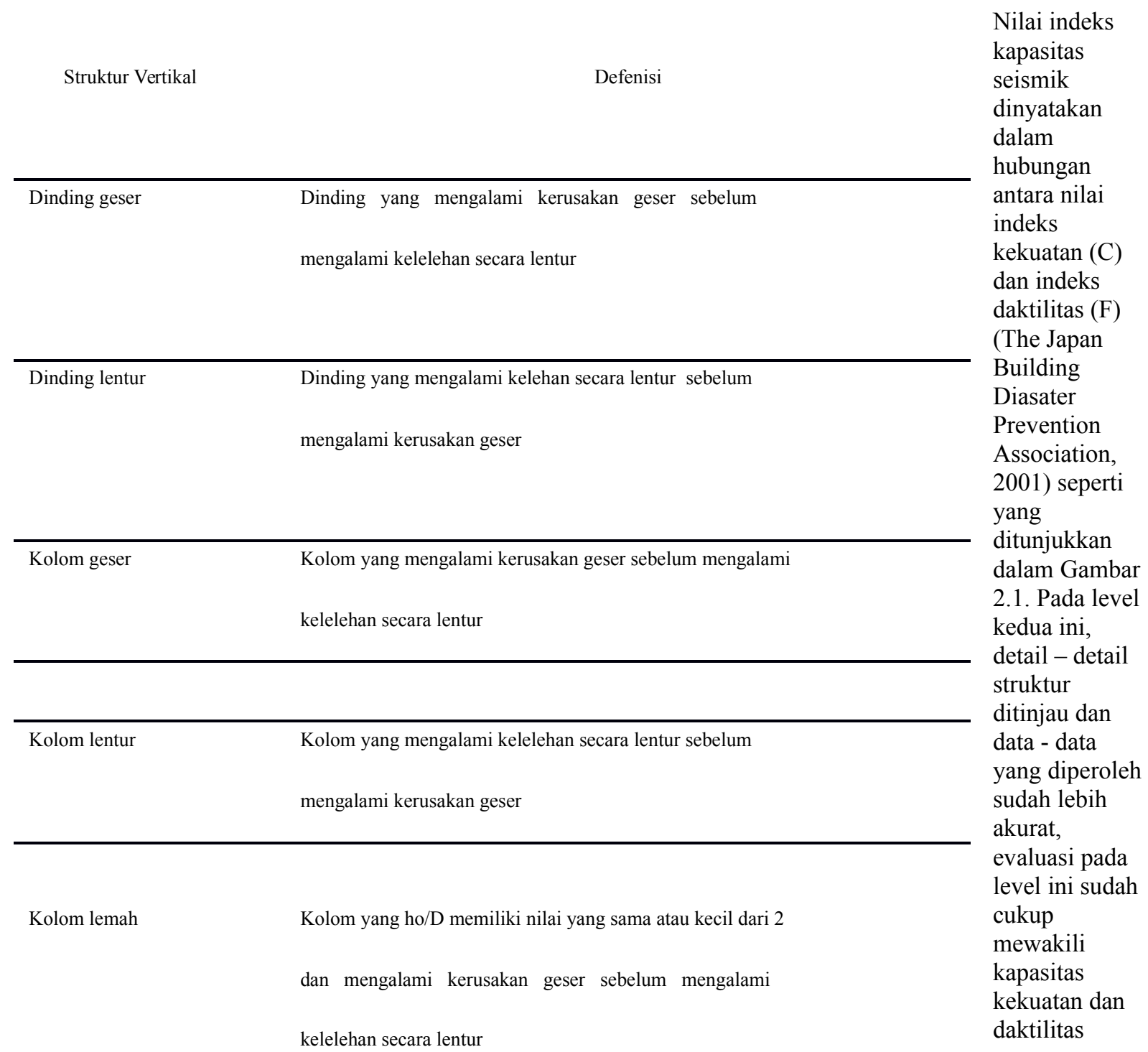

bangunan.dapat dilihat pada gambar 1 . 
Thasbih Al Fajri, Rafki Imani, Zakpar Siregar

Jurnal Teknologi Vol 10 No 2 (2020) 1-6

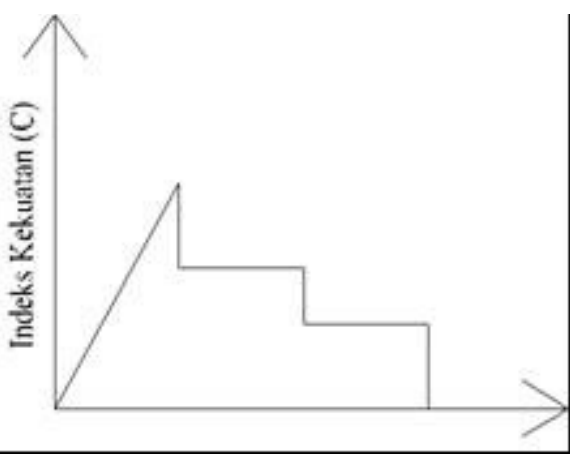

Gambar 1 : Sketsa indeks kekuatan (C) dan indeks daktilitas (F)

Indeks kekuatan (C) pada metoda perhitungan level kedua ini dapat dihitung dengan persamaan berikut : (The Japan Building Disaster Prevention Association, 2001).

$C=\frac{Q_{u}}{\Sigma W}$

Dimana :

$\mathrm{Qu}=$ Kapasitas beban lateral ultimate struktur vertikal pada lantai yang ditinjau berupa nilai terkecil diantara Qmu dan Qsu

$\Sigma \mathrm{W}=$ Berat bangunan termasuk beban hidup untuk perhitungan seismik yang diterima oleh lantai yang ditinjau

\section{Metode Penelitian}

Berdasarkan Standard for Seismik Evaluation Reinforced Concrete Building, 2001, yang diterbitkan oleh The Japan Building Disaster Prevention Association (JBDPA, 2001) digunakan metode level dua, analisis dilakukan pada struktur kolom tanpa memperhitungkan dinding bata, namun untuk dinding persial atau dinding yang hanya sebagian tinggi kolom, diperhitungkan untuk menentukan tinggi bersih kolom. Tahapan analisis kapasitas seismik gedung dapat ditunjukan pada flowchart dalam gambar 2. 
Thasbih Al Fajri, Rafki Imani, Zakpar Siregar

Jurnal Teknologi Vol 10 No 2 (2020 ) 1-6

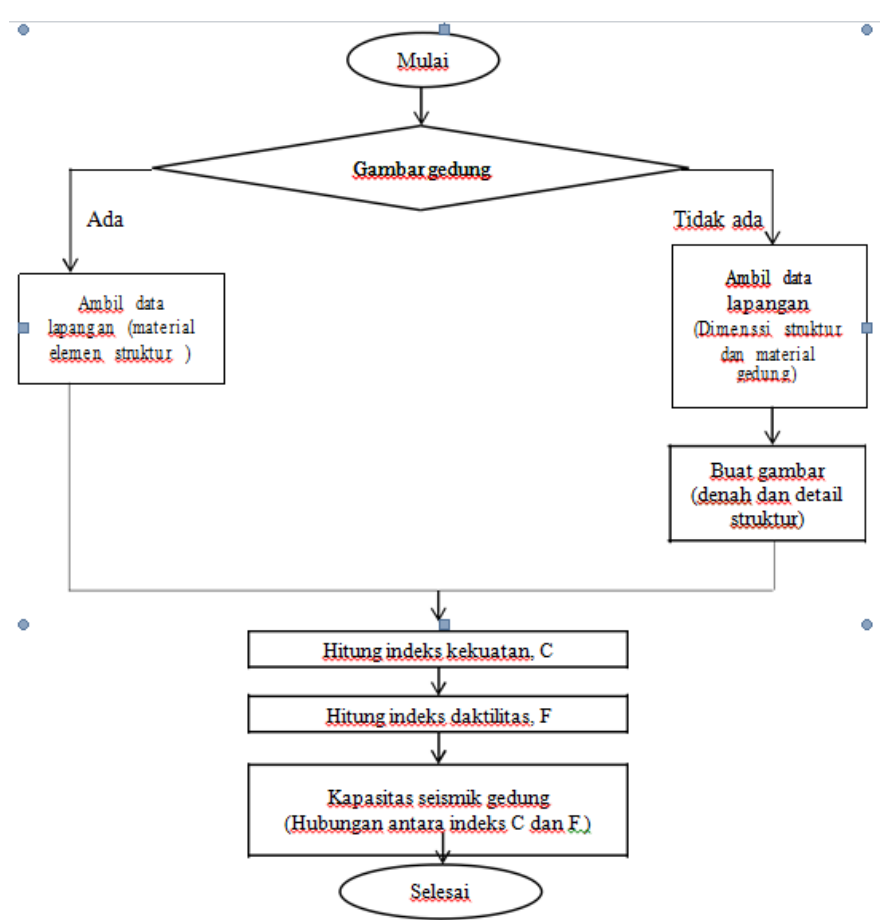

Gambar 2 : bagan alir analisis kapasitas sesimik bangunan beton bertulang ekisting

\section{Hasil dan Pembahasan}

Gedung yang dievaluasi adalah Kantor Dinas Pangan Provinsi Sumatera Barat yang merupakan gedung beton bertulang tiga lantai. Evaluasi dilakukan pada lantai satu, karena kapasitas geser gedung paling besar terdapat pada lantai satu. Evaluasi dilakukan pada arah. utara - selatan. Tampak depan dan tampak samping gedung Kantor Dinas Pangan Provinsi Sumatera Barat ditunjukkan dalam gambar 3 dan gambar 4, untuk denah kolom dan detail kolom lantai satu ditunjukan pada gambar 5 dan gambar 6.

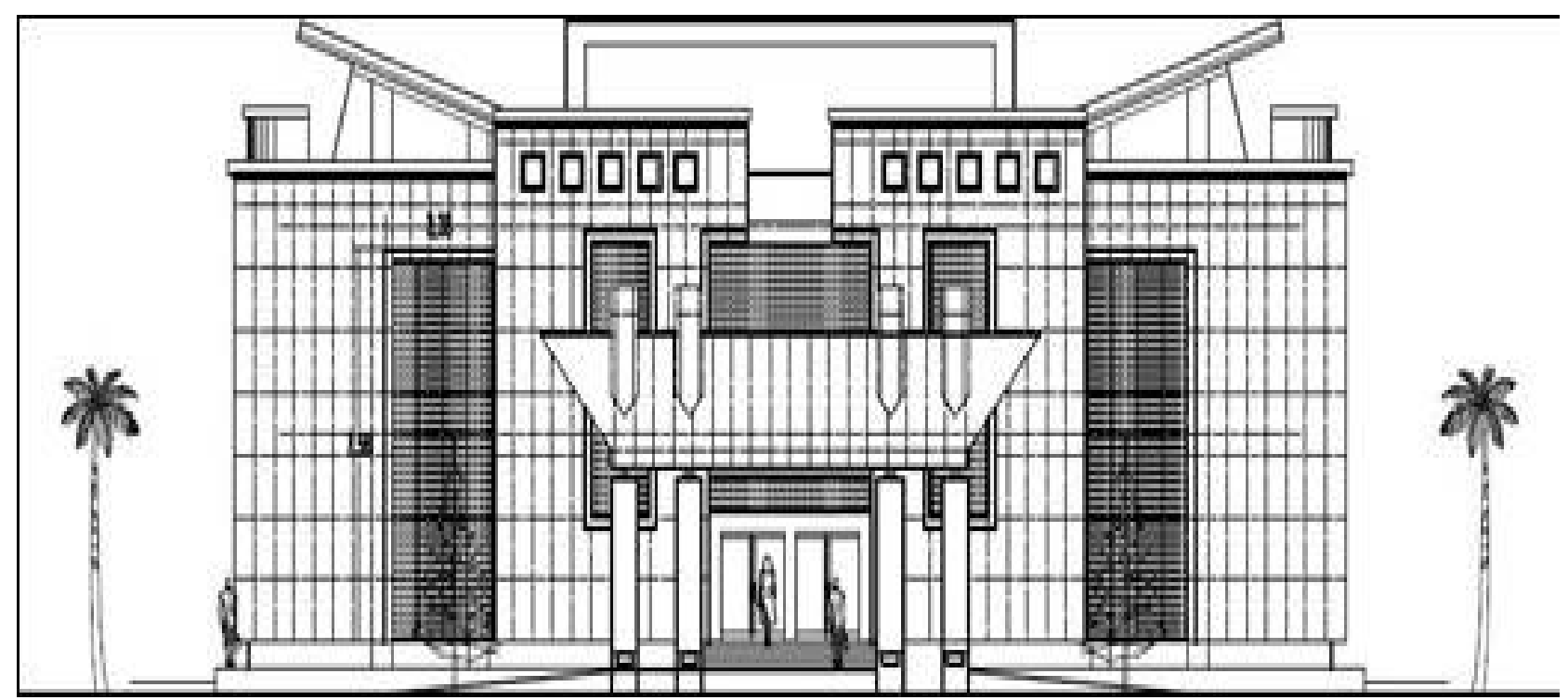

Gambar 3 : Tampak depan 


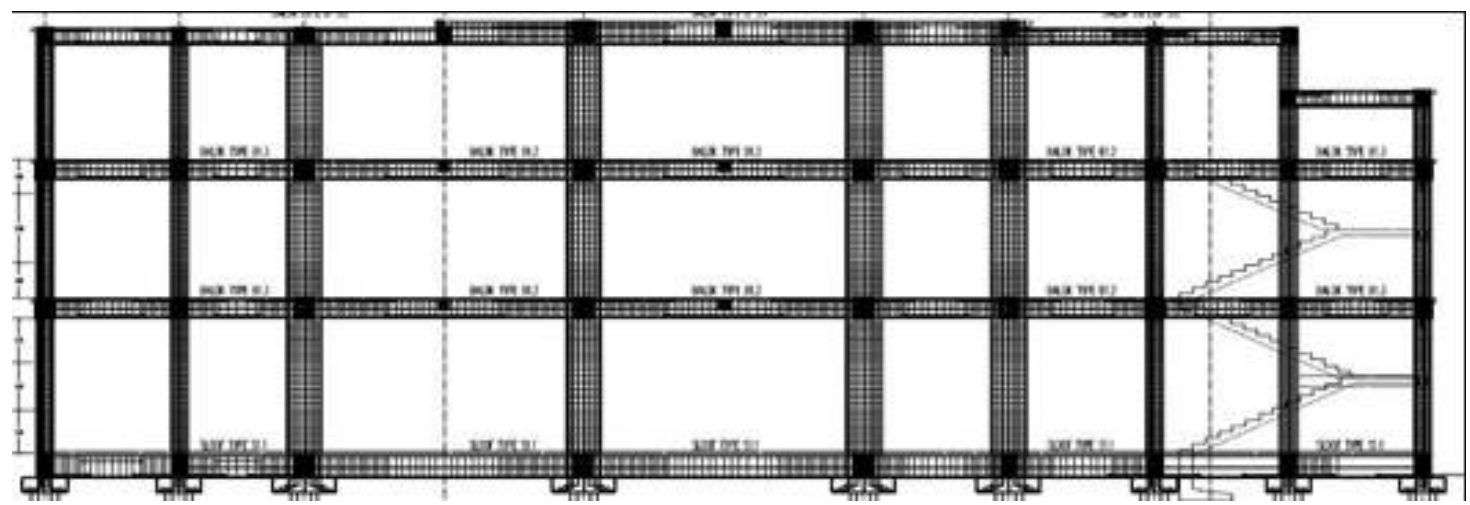

Gambar 4 : Tampak samping

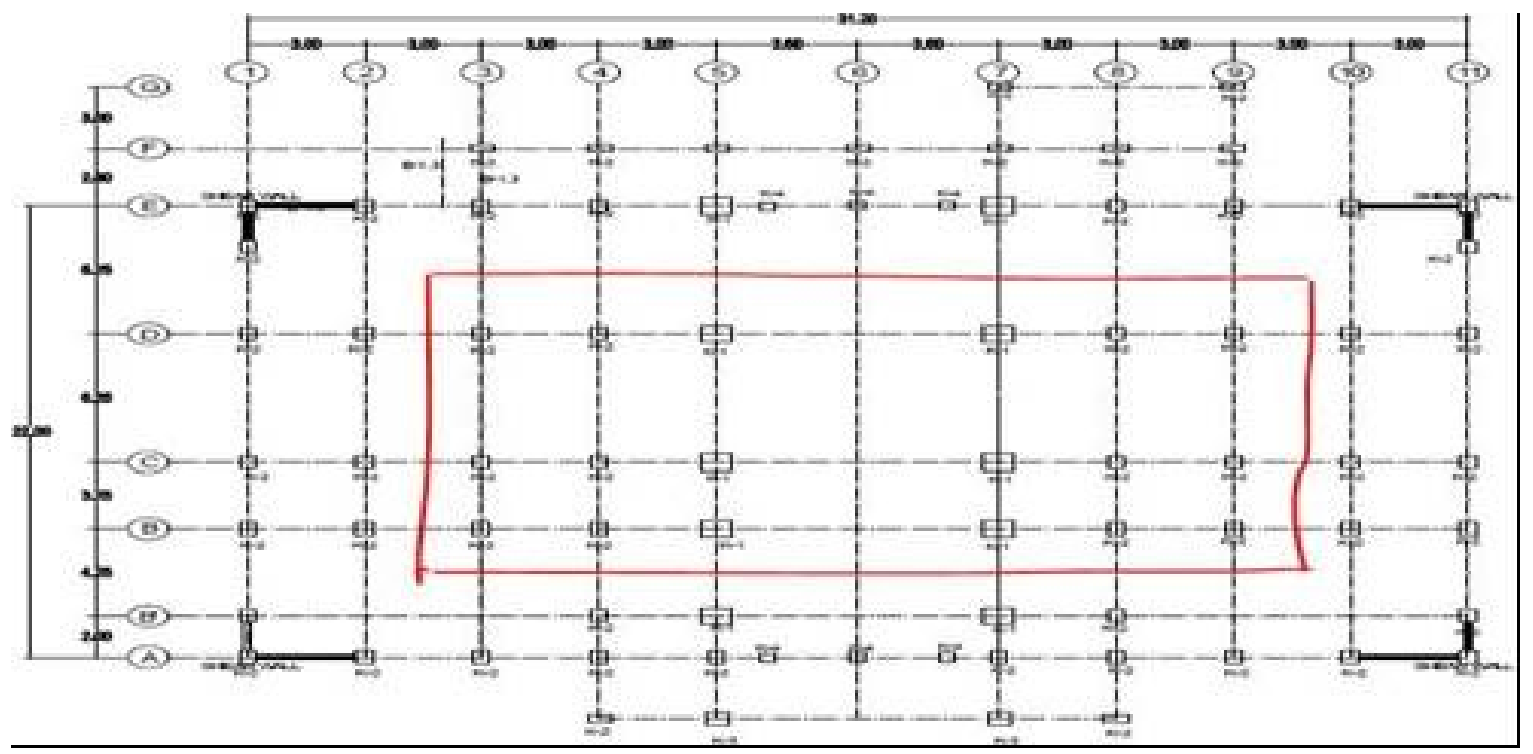

Gambar 5 : Denah kolom lantai satu

\begin{tabular}{|c|c|c|c|c|c|c|c|}
\hline 1 & TYFE & \multicolumn{2}{|c|}{ 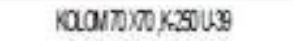 } & 1 & TYF & \multicolumn{2}{|c|}{ 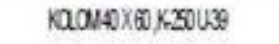 } \\
\hline 2 & PCSS & TURW & LAPAGAI & 2 & PCSS & TUPAI & LAPASWN \\
\hline 3 & PEHAFAG & & & 3 & PEHPAG & & \\
\hline 4 & UKRA & \multicolumn{2}{|c|}{$70 \times 700 \mathrm{l}$} & 4 & UNRAI & \multicolumn{2}{|c|}{$40 \times 600 \mathrm{CN}$} \\
\hline 5 & PANERG & \multicolumn{2}{|c|}{40450 an } & 5 & PAUAG & \multicolumn{2}{|c|}{ ADUS50 ON } \\
\hline 6 & TUAGWITAR & \multicolumn{2}{|c|}{24019} & 6 & TUAGWUTAK & \multicolumn{2}{|c|}{ ADB } \\
\hline 7 & SERAG & $\cos 2 x$ & $0,3-150$ & 7 & SaGWG & $013 \cdot 10$ & 0,320 \\
\hline 8 & SALA & \multicolumn{2}{|c|}{$1: 2$} & 8 & SWA & \multicolumn{2}{|c|}{$1: 20$} \\
\hline
\end{tabular}

Gambar 6 : Detail kolom lantai satu

Kapasitas seismik gedung dinyatakan dalam hubungan indeks kekuatan dan indeks daktilitas pada gambar 7 menunjukan tahapan keruntuhan yang terjadi pada arah utara selatan yang dianalisis. Gedung memiliki indeks kekuatan total sebesar 0,707. Pada indeks daktilitas 3,0, gedung mengalami keruntuhan kolom dengan mengurangi indeks kekuatan sebesar 0,572. Kolom yang runtuh pada indeks daktilitas 3,0 tersebut adalah kolom lentur. Kolom tersebut diantaranya adalah kolom selain dari kolom yan memiliki indeks daktilitas 3.4. Sebagian 
besar kolom arah utara selatan memiliki indeks daktilitas yang besar karena mengalami keruntuhan pada batas indeks daktilitas yaitu 3,4 pada kolom 5-D5 dan 7-D7 yang dapat dilihat pada denah dalam Gambar 5.

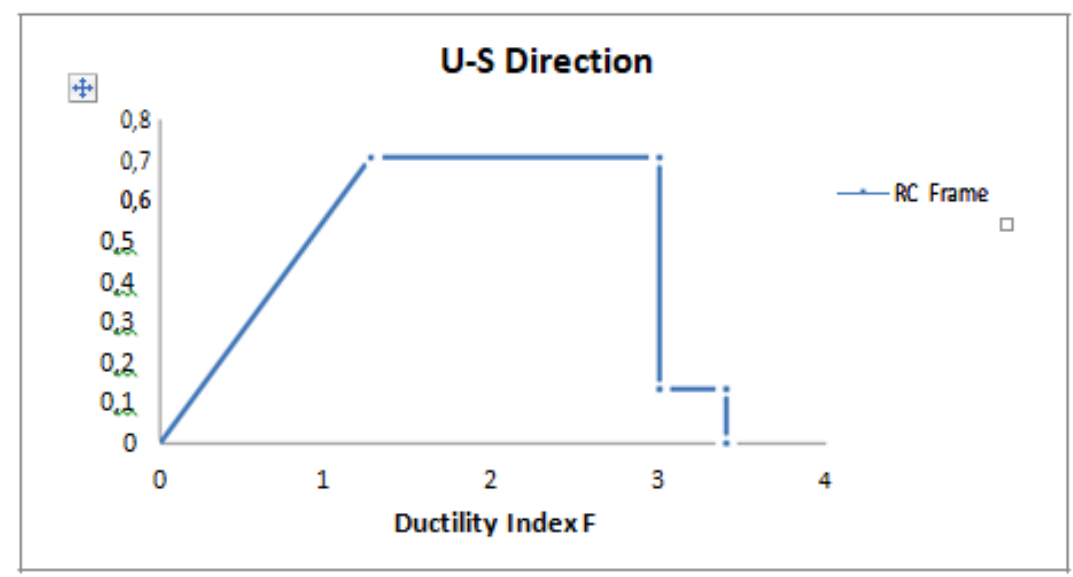

Gambar 7 : Grafik hubungan C dan F arah utara selatan

Keruntuhan kolom ini menyebabkan gedung mengalami penurunan indeks kekuatan secara drastis dengan menyisakan indeks kekuatan gedung sebesar 0,135. Penurunan indeks kekuatan ini dapat menjadi kemungkinan penyebab mengapa gedung beton bertulang roboh ketika digoncang gempa berkekuatan besar tersebut. Gedung terus mengalami keruntuhan kolom pada indeks daktilitas berikutnya seperti yang ditampilkan dalam Gambar 7 sampai semua kolom runtuh pada batas indeks daktilitas 3.4

\section{Kesimpulan}

Berdasarkan hasil anaisis dan evaluasi kaspasitas seismik bangunan Gedung Kantor Dinas Pangan Provinsi Sumatera Barat di dapatkan hubungan nilai antara indeks daktilitas sebagian besar kolom dengan nilai 3,0 dan indeks kekuatan lateral gedung dengan nilai 0,707. Dari hasil evaluasi pada bangunan tersebut yang berlokasi di daearah yang termasuk daearah rawan gempa kuat dengan nilai kapasitas seismik bangunan yang di dapat dari hubungan antara nilai indeks daktilitas dan indeks kekuatan lateral pada gedung yang di evaluasi tersebut dapat dinyatakan mampu berperilaku daktail dan mampu bertahan sewaktu gempa atau tidak mengalami keruntuhan secara tiba-tiba.

\section{Daftar Rujukan}

[1] Agus, 2013, "Rekayasa Gempa. Perencanaan Struktur Gedung Menggunakan Peraturan Terbaru SNI" 13 - 1726 - 2012. Yogyakarta : Andi Offset

[2] Liza, N M., Maidiawati., dan Tanjung, J., 2014, "Evaluasi Kapasitas Seismik Struktur Bangunan Bertingkat Beton Bertulang Eksisting”. Prosiding 1st Andalas Civil Engineering National Conference; Padang, 27 November 2014.

[3] The Japan Building Disaster Prevention Association (JBDPA), 2005, English Version, 1st, Standard for seismic evaluation of existing reinforced concrete buildings, 2001.

[4] Maidiawati, Agus, 2016, "Metoda Evaluasi Kapasitas Seismik Gedung Beton Bertulang Eksisting dengan Aplikasi Model Dinding Bata," Jurnal Teknik Sipil ITB Vol. 23, Bandung

[5] Akbar, F. A., 2017, “Tugas Akhir Analisis Kontribusi Dinding Batu Bata terhadap Kekuatan Lateral Gedung Beton Bertulang (Studi Kasus Gedung Perkuliahan Institut Teknologi Padang)”. Padang : Institut Teknologi Padang. 
